\title{
Green Roof Concepts as a Passive Cooling Approach in Tropical Climate- An Overview
}

\author{
Noorazlina Kamarulzaman ${ }^{1}$, Siti Zubaidah Hashim ${ }^{2}$, Hasnan Hashim ${ }^{3}$, Alia Abdullah Saleh ${ }^{4}$ \\ ${ }^{1,2,3,4}$ Department of Building Surveying, Faculty Architecture, Planning and Surveying, UiTM Seri \\ Iskandar, Malaysia
}

\begin{abstract}
Nowadays, increasing of energy consumption due to global warming issues such as heat island effects has attracted the awareness of researchers, architects, engineers, property developers, and authorities to the crucial of green construction or sustainable development concept. Energy efficiency has been identified as a key consideration in discussions of this concept. In term of energy, Malaysia ranked $33^{\text {rd }}$ in the list of global electricity consumption and $25^{\text {th }}$ in the list of man-made carbon dioxide emissions. If energy consumption continues to increase at its current rate, domestic petroleum reserve in Peninsular Malaysia is predicted to be depleted by 2014 and Sarawak by 2020 [1]. As responding to the increasing of energy consumption, the demand of green roof technology as passive cooling technique has been recognized worldwide. Generally, by greening the rooftops in urban area, the impact on the urban climate and microclimate as well as on the indoor climate of buildings beneath them will be reduced. Therefore, this paper systematically review the concepts of green roof to give a basic understanding as global. Discussion on the benefits of this concept and its components among topic will be discussed.
\end{abstract}

\section{Introduction}

Phenomenon of global warming or climate change such as higher atmospheric temperatures, increase greenhouse gas emission and intensive precipitation has grabbed peoples attention and become critical worldwide. According to Maslin [2], the mean global temperature has increased by about 0.3 to $0.6{ }^{0} \mathrm{C}$ since the late of 19 th century and the high of temperature, rising of sea level and abundant precipitation are the indicators of global warming. Santamouris [3] mentioned that heat island is the most documented phenomenon of climate change. The phenomenon is known for almost a century and is related to higher urban temperatures compared to the adjacent suburban and rural areas. Several studies have analyzed that higher urban temperatures increase the energy consumption for cooling and raise the peak electricity demand.

Globally, buildings are responsible for approximately $40 \%$ of the total world annual energy consumption. Most of this energy is for the provision of lighting, heating, cooling, and air conditioning. According to Biro Maklumat Tenaga Malaysia, higher energy consumption in office building in Malaysia is due to the air-conditioning system whereby it's contribute to $64 \%$ from the overall energy consumption. Meanwhile, air-conditioning represents $23 \%$ of energy used for residential building. In Europe, buildings represent $40 \%$ of the overall energy consumption and $36 \%$ of the overall $\mathrm{CO} 2$ emissions [4]. United States Green Building Council (USGBC), estimated that 
commercial and residential construction buildings release $30 \%$ of greenhouse gases and consumes $65 \%$ of electricity in USA. Announcement by the Prime Minister, Y.A.B Datuk Seri Najib Tun Razak in Denmark in 2009 to reduce carbon dioxide emissions $40 \%$ by 2020, was a brilliant move and shows the commitment of the government in addressing environmental issues at the global level. To counterbalance the phenomenon, several ways either active or passive constructions have been developed and proposed. Among them, Green Roofs Technology appears as a natural and sustainable way to help urban centres respond to climate change and improve urban environmental quality. This technology is more popular across Europe over the past few decades. In contrast, implementation of this technology in Malaysia is still new and scant.

\section{What Is a Green Roof?}

Green roofs, also known as eco-roofs, living roofs, planted roofs or vegetated roofs, use plants to improve a roof's performance, its appearance, or both. As mentioned by Dunnett and Kingsbury [5], green roofs is a planted roof or green roof can be defined as a roof that consists of vegetation and growing medium and sometime refers to the roof garden in some places. It is a flat or sloping rooftop designed to support vegetation In addition to their ecological characteristics, green roofs are sophisticated systems that are designed to provide a fully functioning roof. They are made up of several membranes (waterproofing, root-barrier, drainage and filter membranes) onto which a substrate layer is placed to allow vegetation to grow [6]. Meanwhile, Oberndorfer et al., [7] defined green roof as a flat or sloped rooftop designed to support vegetation. Soil depths can range from a few centimeters for a dense mat of succulent plants to $20 \mathrm{~cm}$ to $1 \mathrm{~m}$ or even deeper for more intensively managed roof gardens. Green roof systems have been shown to provide many ecosystem services such as improved storm water management, reduced energy usage for cooling, reduced urban heat island effects, and wildlife habitat.

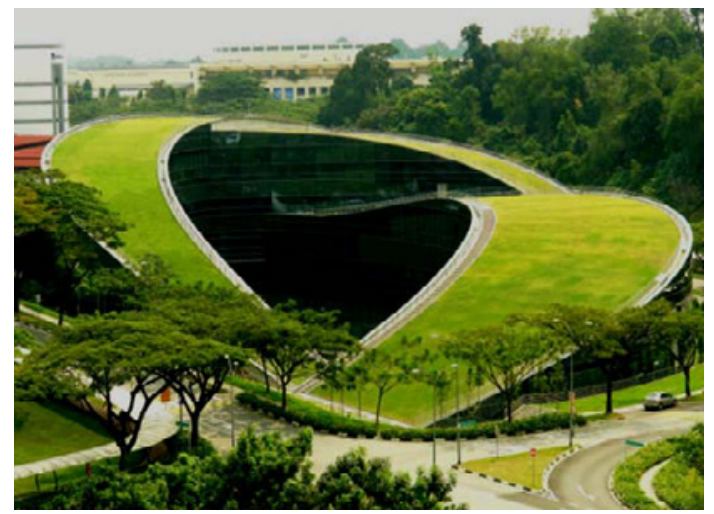

Figure 1: Extensive green roof at School of Art, Design \& Media, Nanyang Technological University, Singapore

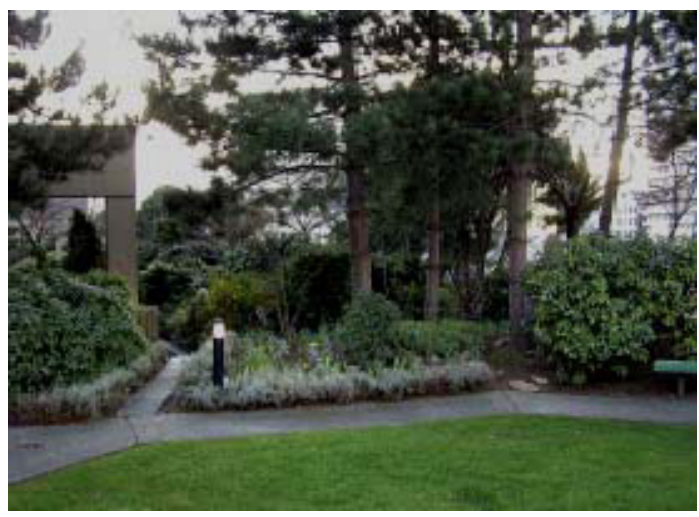

Figure 2: Intensive green roof on the Coast Plaza Hotel in Vancouver, British Columbia

Green roof can be divided into two distinguished types which are either considered as extensive or intensive (refer figure land 2). Extensive roofs which are light and are covered by a thin layer of vegetation and intensive roofs which are heavier and can support small trees and shrubs. In addition, intensive green roof also being known as roof garden can only be built on the roofs of building that are strong enough to support the load. They are ideally suited to reinforced-concrete structures and steel frame. However, with the technological advances, they can be built on the various types of structures. Extensive green roofs with a substrate layer with a maximum depth of about $150 \mathrm{~mm}$, with usually Sedum species as the major part of the vegetation. Intensive green roofs with a substrate layer with a depth of more than $150 \mathrm{~mm}$, and usually grasses, perennial herbs and shrubs make up the main 
constituents of the vegetation [8][9]. Besides that, D.J. Sailor [10] defined the green roof growing medium depth is typically between 10 and $30 \mathrm{~cm}$, although some implementations (referred to as intensive green roofs) have deeper soils capable of sustaining large shrubs and even trees. The thinner implementations (typically $<20 \mathrm{~cm}$ ), known as extensive green roofs, are more common, but can only sustain smaller plants and ground cover. The differences between extensive and intensive green roofs are summarized in the Table 1 below.

Table 1: Summarized of the differences between extensive and intensive green roofs

\begin{tabular}{|l|ll|}
\hline \multicolumn{1}{|c|}{ Intensive Green Roof } & & \multicolumn{1}{c|}{ Extensive Green Roof } \\
\hline - $\begin{array}{l}\text { Require intensive maintenance } \\
\text { Accessible }\end{array}$ & - & Require extensive maintenance \\
- $\begin{array}{l}\text { Require deeper substrate }(\min 15 \mathrm{~cm}) \\
\text { Heavy weight }(\text { saturated weight } \\
\text { between } 200 \text { to } 500 \mathrm{~kg} / \mathrm{m} 2) \\
\text { High cost }\end{array}$ & - & - Require shallow substrate $($ only $2-15 \mathrm{~cm})$ \\
Low weight $\left(\right.$ saturated weight between $\left.60-150 \mathrm{~kg} / \mathrm{m}^{2}\right)$ \\
\hline
\end{tabular}

Source: Werthmann, 2007\& German National Standard DIN 1055

\section{Green Roof Benefits}

Generally, green roofs entail growing plants on rooftops, which partially replaces the vegetation that was destroyed when the building was constructed. In doing so they provide numerous benefits that can help offset the negative aspects of pollution, especially in the urban environment. They can improve storm water management by reducing runoff and improving water quality, conserve energy, mitigate the urban heat island, increase longevity of roofing membranes, reduce noise and air pollution, sequester carbon, increase urban biodiversity by providing habitat for wildlife, provide a more aesthetically pleasing environment to work and live, and improve return on investment compared to traditional roofs [11]. The benefits of green roof as mentioned by D. Bradley Rowe were agreed by worldwide researchers as follows:

\subsection{Storm water management}

Current research underway at North Carolina State University in storm water management suggests, for example, that green roofs with 4 in. $(10 \mathrm{~cm})$ of substrate retain as much as 60 percent of all rainwater, which has tremendous potential for addressing storm water runoff and water quality. Lin Y-J et. al., [12] \& Carter T et. al., [13] has mentioned in their research that by absorbing rainwater in their substrate, green roofs delay the runoff and mitigate the impact of heavy rains, which affect urban areas with impermeable soils. Green roofs also decrease the risk of floods, duct overloading and water reprocessing. Although many studies have demonstrated that green roofs can retain rainfall, but the quantity retained depends on many variables, such as substrate depth, type of vegetation and duration and intensity of precipitation. This variation prevents generalizations being made about the efficiency of green roofs in this respect [14].

\subsection{Aesthetic and practical benefits.}

Green roof provides habitat for birds and insects, sequesters carbon dioxide and other pollutants, purifies the air, and produces oxygen and returns moisture and coolness to the air through evapotranspiration. In Europe, where populations are more densely concentrated, intensive and extensive green roofs are also frequently designed as recreational or open spaces, and playgrounds over underground parking garages. Meanwhile, other researchers stated that green roofs also have a 
positive impact towards people living or working in the green buildings than in buildings that are less environmentally friendly in term of worker productivity.

\subsection{Mitigation of the urban heat island effect}

Green roofs is that their presence allows for evapotranspiration, and the resultant humidification and air cooling will, in turn, reduce the heat island effect. In urban areas, this effect increases night temperatures in the heart of the city [15]

\subsection{Reduce noise pollution}

The hard surfaces of urban areas tend to reflect sound rather than absorb it. Green roofs can absorb sound, however with both substrate and plants making a contribution, the former tending to block lower sound frequencies and the latter higher ones. Some extravagant claims are made about the ability of green roofs to reduce noise. For example, it has been stated that a green roof with a $12 \mathrm{~cm}$ (4.8in) substrate layer can reduce sound by 40 decibels while a $20 \mathrm{~cm}$ ( 8 in) layer can reduce by $46-50$ decibels [16].

\subsection{Thermal reduction and thus energy saving.}

The green roof technology is also able to reduce the energy consumption and to improve the internal comfort during the spring and summer seasons, in sites where the climatology is characterized by high temperature and irradiance values during the day [17]. Few studies were investigated in the Southern hemisphere where the green roof potential as a natural cooling is unknown or poorly known. Wong et al. [15]) explored the thermal benefits of a green roof in Singapore through an experimental test done before and after the construction of a rooftop garden. That study concluded that the thermal protection of plants also highly depends on their leaf area index (LAI) since lower temperatures were found under dense trees and shrubs as compared to sparse foliages

\section{Components of a Green Roof}

A green roof is an engineered system that must meet basic roofing requirements. The system includes layers that protect building from leaks, allow excess water drain, retain sufficient water to support the vegetation, prevent plant roots from penetrating the roof membrane and in some cases insulate the building. Green roofs typically comprise the basic components as shown in Figure 3 below :

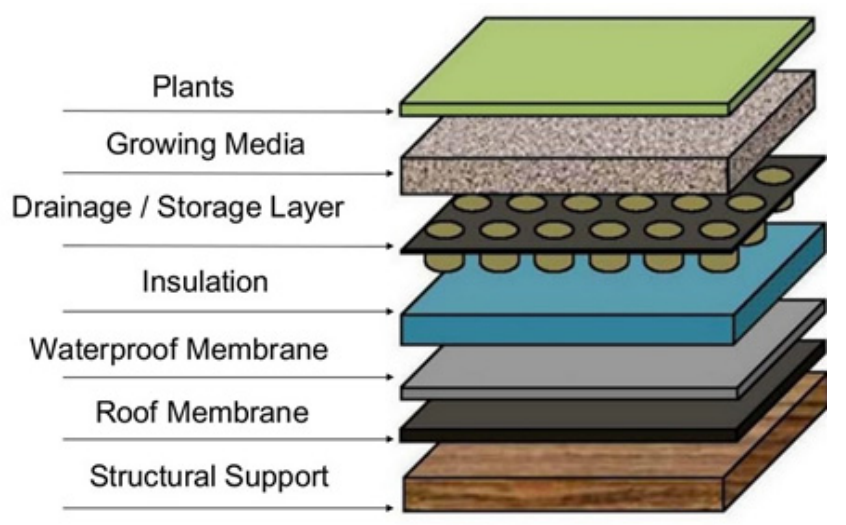

Figure 3: Basic components of typical Green Roof 


\section{Green Roof as a Passive Cooling Method}

Green roofs can offer a sustainable green surface by improving urban climate, minimizing heat island effects and simultaneously protecting biodiversity. Many studies have demonstrated that a green roof is able to reduce the energy consumption by lowering the thermal absorption and improve the internal comfort of buildings. As stated by Eumorfopoulou and Aravantinos [18], by providing large surfaces with vegetation, they contribute to the improvement of thermal performance of buildings. This finding was supported by Niachou A, et al [19], which discovered the indoor temperature values in the building with green roof are lower during the day. They measured the roof temperatures in non-insulated building with and without green roof. The result shows that the surface temperature of non-insulated building without green roof are varied from 42 to $48^{\circ} \mathrm{C}$ while the surface temperatures of the green roof upon non-insulated building are lower and ranging from 28 to $40^{\circ} \mathrm{C}$. They also concluded that the existence of large temperature differences due to the installation of green roof could contribute to energy saving potential [20].

Several properties of green roofs contribute to their thermal characteristics; direct shading of the roof, evaporative cooling from the plants and the growing medium, additional insulation values from both the plants and the growing medium, and the thermal mass effects of the growing medium [21]. Differences in these factors can have important effects on the roof's performance [5]. A group of researchers from Japan has conducted the field measurements of roof lawn garden planted on nonwoven fabric on an actual three-storey pre-cast reinforced concrete building. From the measurements, it confirmed that the amount of heat coming into room during summer was reduced by a roof lawn garden.

The reduction of roof slab surface temperature from 60 to $30^{\circ} \mathrm{C}$ was observed during the measurement and estimation of 50 percent in heat flux was calculated by simple calculation [22]. Another study on the thermal performance of extensive rooftop greenery systems has been conducted in Singapore by Wong. That study concluded that the green roof tends to experience lower surface temperature than the original exposed roof surface. In areas well covered by vegetation, over 60 percent of heat gain was prevented by the implementation of green roof system. According to that study, the heat flux through the roof structure was greatly reduced after the installation of the green roof system [20].

Spala et al [23] found that the installation of green roof on the office building in Athens presents a significant contribution to the energy saving during summer period. The remarkable reduction of the building cooling load was estimated during the simulation study. However, during winter, the effect of green roof installation is not significant because of the variation of heating load was quite small. Green roof also can effectively reduce the need for air conditioning in summertime thus contribute to energy saving in building [21] Liu, in another study, made a conclusion that green roofs are giving better performance in the summer than in the winter because the ability of reducing heat gain than heat loss [24]. Researchers also proved that plants and substrates are the major contributor to the thermal performance and energy reduction aspect.

\section{Conclusion}

As a conclusion, the issue of increasing energy consumption in the building is due to the increasing outdoor temperature and it's related to environmental issues such as global warming and heat island. Most of the researchers worldwide collectively agreed that one way of reducing the impact of global warming and heat transfer into the building is by implementing green roof technology. However, as stated by Czemiel Berndtsson et al. [25], the effects of green roofs on energy consumption through thermal reduction are influenced by the type of vegetation used, climate, intensity and duration of precipitation, substrate depth, and also the type of building. That statement 
was supported by M. Santamouris [3] which indicated that the specific energy benefits depend on the local climate, the green roof design and more importantly on the specific building characteristics. Hence, further research on the performance of thermal reduction and plant characteristics suitable to the Malaysia climatic condition is crucial to be studied.

\section{References}

1) UNDP \& EPU, (2005), Malaysia: Achieving The Millennium Development Goals-Successes And Challenges, Kuala Lumpur, United Nations Country Team, Malaysia.

2) Maslin, M. (2004) Global Warming: A Very Short Introduction, New York, Oxford University Press.

3) Santamouris, M. (Ed.), 2001. Energy And Climate In The Urban Built Environment. James And James Science Publishers, London

4) Chen Gq, Chen H, Chen Zm, Zhang Bo, Shao L, Guo S, (2011) Low-Carbon Building Assessment And Multi-Scale Inputeoutput Analysis. Commun Nonlinear Sci Numer Simul 16(1) : 583-595

5) Dunnett, N. \& kingsbury, N. (2004) Planting Green Roofs and Living Walls, Portland, Timber Press.

6) Dvorak, B., Volder, A., 2010. Green roof vegetation for North American ecoregions: a literature review. Landscape and Urban Planning 96, 197e213

7) Oberndorfer, E., Lundholm, J., Bass, B., Coffman, R., Doshi, H., Dunnett, N., et al., 2007. Green roofs as urban ecosystems: ecological structures, functions, and services. Bioscience 57 (10), 823-833.

8) Krupka B, Dachbegr“Unung. Pflanzen-Undvegetationsanwendung An Bauwerken. Stuttgart :Ulmer; 1992

9) Kolb W., Schwarz T. Dachbegr“Unung, Intensiv Und Extensiv. Stuttgart :Ulmer; 1999.

10) D. J. Sailor (2008). A Green Roof Model For Building Energy Simulation Programs. Energy And Buildings 40 : 1466-1478.

11) D. Bradley Rowe (2011). Green roofs as a means of pollution abatement. Environmental Pollution 159:2100-2110

12) Lin Y-J, Lin H-T. (2011) Thermal performance of different planting substrates and irrigation frequencies in extensive tropical rooftop greeneries. Building Environment. 46(2):345-355.

13) Carter T, Jackson CR. (2007) Vegetated roofs for stormwater management at multiple spatial scales. Landscape Urban Plann 80(1-2):84-94.

14) Carter, T., Fowler, L., 2008. Establishing green roof infrastructure through environmental policy instruments. Environmental Management 42, 151-164.

15) Wong NH, Chen Y, Ong CL, Sia A. Investigation of thermal benefits of rooftop garden in the tropical environment. Building Environ 2003;38(2):261-270.

16) Peck, S.P (2003). Private benefits, public benefits. Available via http:// www.peck.ca.grhcc.

17) Onmura S, Matsumoto M, Hokoi S. (1994) A study on evaporative cooling effect by roof lawn garden. Proceedings of the European conference on energy performance and indoor climate in buildings $634-639$.

18) Eumorfopoulou, E. \& Aravantinos, D. (1998) The Contribution Of A Planted Roof To The Thermal Protection Of Buildings In Greece. Energy And Buildings, 27 : 29-36.

19) Niachou, A., Et Al. (2001) Analysis Of The Green Roof Thermal Properties And Investigation Of Its Energy Performance. Energy And Buildings, 33 : 719-729.

20) Asmat Ismail, M. H. A. S. A. A. M. A. R. (2008). Using Green Roof Concept As A Passive Design Technology To Minimise The Impact Of Global Warming. 2nd International Conference On Built Environment In Developing Countries (ICBEDC 2008). 
21) Liu, K. \& Baskaran, B. (2003) Thermal Performance Of Green Roofs Through Field Evaluation. Greening Rooftops For Sustainable Communities," The First North American Green Roofs Infrastructure Conference, Awards, And Trade Show, Chicago, IL, May, 29-30.

22) Onmura, S., Et Al. (2001) Study On Evaporative Cooling Effect Of Roof Lawn Gardens. Energy And Buildings, 33 : 653-666.

23) Spala, A., Et Al. (2008) On The Green Roof System. Selection, State Of The Art And Energy Potential Investigation Of A System Installed In An Office Building In Athens, Greece. Renewable Energy, 33 : 173-177.

24) Liu, K. (2006) Thermal Performance Of Green Roofs In Canada. British Columbia Institute Of Technology

25) Czemiel Berndtsson, J., Bengtsson, L., Jinno, K., 2009. Runoff water quality from intensive and extensive vegetated roofs. Ecological Engineering 35 : 369-380. 